\title{
Dinâmica da associação de capim-milhã e capim-de-raiz em pasto diferido ${ }^{1}$
}

\author{
Marta Gerusa Soares da Silva², Mario de Andrade Lira ${ }^{3,7}$, Mércia Virginia Ferreira dos \\ Santos $^{4,7}$, José Carlos Batista Dubeux Junior ${ }^{4,7}$, Manuela Menezes Lins ${ }^{5}$, Camilla Vila Nova \\ Soares Silva 6
}

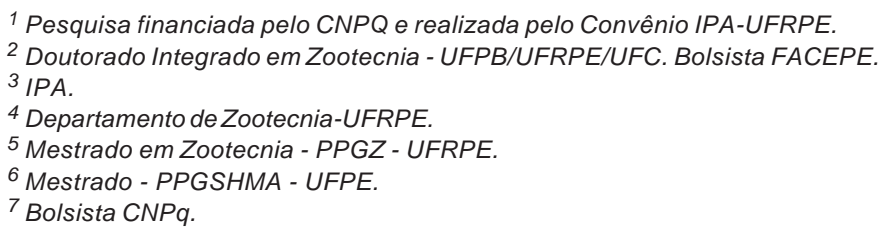

RESUMO - Este estudo foi realizado com o objetivo de avaliar a dinâmica da associação capim-de-raiz (Chloris orthonoton Doell) e capim-milhã [Brachiaria plantaginea (Link) Hitchc] quanto à persistência e produção. Em pasto nativo diferido, foram realizadas a coleta do material botânico, avaliação da composição botânica e massa de forragem. Para estimativa da massa de forragem, utilizou-se delineamento de blocos ao acaso, com quatro tratamentos; 60, 90, 120 e 150 dias de diferimento; e cinco repetições. Na composição botânica, expressa em percentual do total, foram identificadas 10 famílias, 15 gêneros e 18 espécies. No período de maio a agosto de 2007, o capim-milhã foi o componente principal dos 60 aos 90 dias, correspondendo a 46,75 e 52,09\%, respectivamente, da composição botânica total. Em agosto de 2007, outras espécies participaram com 57,75\% da composição botânica. No ano de 2008, ao final do período de diferimento, outras espécies ocuparam 100\% da composição botânica do pasto. As maiores massas de forragem (kg de MS/ha) para o capim-milhã (2.736) foram aos 90 dias, para outras espécies (3.141) e capim-de-raiz (2.701) aos 120 dias. O aproveitamento da forragem acumulada deve ocorrer preferencialmente dos 60 aos 90 dias. Após um ano sem interferência, o capim-de-raiz e o capim-milhã diminuem a participação na composição botânica do pasto.

Palavras-chave: composição botânica, diferimento, gramíneas, pastagem nativa

\section{Dynamics of the association of alexandergrass and capim-de-raiz on deferred grazing}

\begin{abstract}
This study aimed to evaluate the dynamics of the association of 'capim-de-raiz' (Chloris orthonoton Doell) and alexandergrass [Brachiaria plantaginea (Link) Hitchc], as for persistence and production. Gathering of botanical material, evaluation of botanical composition and forage mass were realized in deferred native pastures. To estimate forage mass, a randomized block design with four treatments was used, consisting of 60, 90, 120 and 150 days of deferring and five replications. The botanical composition was expressed as a percentage of the total. Ten families, 15 genera, and 18 species were identified. In the botanical composition from May to August 2007, alexandergrass was the main component from 60 to 90 days, corresponding to 46.75 and 52.09\%, respectively. In August 2007, other species participated with 57.75\% of the botanical composition. In the assessment of the year 2008, at the end of the deferring period, other species occupied $100 \%$ of the botanical composition of pasture. The highest forage mass (kg DM/ha) for alexandergrass $(2,736)$ occurred at 90 days; for other species $(3,141)$ and 'capim-de-raiz' $(2,701)$, it was at 120 days. The use of stockpiled forage should preferably take place after 60 to 90 days of deferring. After a year without interference, 'capim-de-raiz' and alexandergrass decrease participation in the botanical composition of pasture.
\end{abstract}

Key Words: botanical composition, deferring, grass, native pasture

\section{Introdução}

O estudo da disponibilidade da fitomassa das espécies predominantes na caatinga possibilita melhor manejo das forrageiras nativas dessa região, notadamente em área de caatinga que foi destruída total ou parcialmente, onde surge vegetação espontânea formada por pasto natural produtor de fitomassa forrageira (Marques, 2007).

Desse modo, o entendimento ecológico dos processos que envolvem produtividade das pastagens 
nativas, presença de cobertura vegetal, valor forrageiro, limitações do ambiente e das suas aceitações, bem como o processo natural de sucessão, é a base para o manejo (Maraschin, 1993).

Sabe-se que o estudo da composição botânica descreve a ocorrência das espécies em determinada área, sendo considerada a melhor propriedade para identificar sítios ecológicos. Como medida dinâmica, a composição botânica pode ser usada para detectar mudanças a eles impostas, visto que as associações das espécies dependem do meio ambiente. A composição botânica é expressa em termos florísticos e pode ser medida quantitativamente por meio da frequência de ocorrência, do número, da densidade, da cobertura e do peso (Tothil, 1979).

O capim-de-raiz (Chloris orthonoton Doell) é uma gramínea nativa do semiárido nordestino presente em grandes áreas de pastagens do Agreste e Sertão de Pernambuco (Santos et al., 2010), sendo capaz de produzir quantidades consideráveis de forragem. Apesar de fazer parte da alimentação dos rebanhos do semiárido pernambucano, essa gramínea tem sido pouco estudada, por isso, há poucas informações dsponíveis, principalmente quanto ao seu manejo (Oliveira et al., 2004).

Segundo Fernandes et al. (1983) e Albuquerque et al. (2002), no Agreste de Pernambuco, o capim-de-raiz ocorre em associação com outras espécies, em extensas áreas de pastagens nativas herbáceas, sendo frequentemente 0 principal componente da pastagem.

Entre as espécies que ocorrem em associação com o capim-de-raiz, trabalhos de levantamento botânico do estrato herbáceo da caatinga têm evidenciado a presença do capim-milhã [Brachiaria plantaginea (Link) Hitch] (Silva et al., 1999; Araújo Filho et al., 2002; YdoyagaSantana et al., 2011).

Este trabalho foi realizado com o objetivo de avaliar a dinâmica da associação capim-milhã e capim-de-raiz, quanto à persistência e produção, no Agreste de Pernambuco.

\section{Material e Métodos}

A pesquisa foi realizada na Estação Experimental do Instituto Agronômico de Pesquisa-IPA, município de São Bento do Una, Agreste de Pernambuco, situado nas seguintes coordenadas geográficas: latitude $08^{\circ} 31^{\prime} 16^{\prime \prime} \mathrm{S}$, longitude 36³3'33" W e altitude de $650 \mathrm{~m}$. O clima da região, segundo Thornthwaite \& Mather (1955), é DdA’a’ semiárido megatérmico e o solo predominante é classificado como planossolo (Silva et al., 2001).

Os estudos foram realizados no período de maio a agosto de 2007 e maio a agosto de 2008. As precipitações médias anuais foram de $618 \mathrm{~mm}$ e 683,9 $\mathrm{mm}$ para os anos 2007 e 2008, respectivamente.

A amostra de solo da área experimental foi coletada a $20 \mathrm{~cm}$ de profundidade e a análise de fertilidade apresentou os seguintes resultados: $\mathrm{pH}$ (água) $=5,83, \mathrm{P}=290 \mathrm{mg} / \mathrm{dm}^{3}$, $\mathrm{Na}^{+}=0,43 \mathrm{cmol}_{\mathrm{c}} / \mathrm{dm}^{3}, \mathrm{~K}^{+}=1,28 \mathrm{cmol}_{\mathrm{c}} / \mathrm{dm}^{3}, \mathrm{Ca}^{+2}=$ $3,00 \mathrm{cmol}_{\mathrm{c}} / \mathrm{dm}^{3} \mathrm{e} \mathrm{Al}^{+3}=0,10 \mathrm{cmol}_{\mathrm{c}} / \mathrm{dm}^{3}$. Provavelmente, esta alta fertilidade foi decorrente do acúmulo sucessivo de esterco em áreas onde os bovinos dormiam.

A área experimental era de pastagem nativa, com presença previamente conhecida de capim-milhã e capimde-raiz. Era utilizada para pastejo de bovinos da Estação Experimental e, em novembro de 2006, parte da área de pastagem foi diferida, formando a área experimental, com aproximadamente $80 \mathrm{~m}^{2}$.

Uma coleta do material botânico de todas as espécies foi realizada na área para estudo da composição florística, aos 60 dias após as chuvas de março dos anos 2007 e 2008. Os materiais foram encaminhados para identificação no herbário Dárdano de Andrade Lima, do Instituto Agronômico de Pernambuco - IPA.

A composição botânica foi avaliada nos períodos de maio a agosto de 2007 e maio a agosto de 2008 e a massa de forragem, no período de maio a agosto de 2007. As avaliações da composição botânica e da massa de forragem foram realizadas aos 60, 90, 120 e 150 dias após o início das chuvas de março de cada ano, quando as plantas podiam ser facilmente identificadas.

A composição botânica foi obtida utilizando-se a metodologia do peso seco escalonado, proposta por T’Mannetje \& Haydock (1963), enquanto a estimativa de massa de forragem foi obtida pelo método direto de corte.

A área experimental foi dividida em 20 subáreas experimentais de $4 \mathrm{~m}^{2}(2 \mathrm{~m} \times 2 \mathrm{~m})$. Nas determinações da massa de forragem (kg/ha) e composição botânica da área, foram considerados os seguintes componentes: i) capimde-raiz (Chloris orthonoton Doell); ii) capim-milhã [Brachiaria plantaginea (Link) Hitchc]; iii) outras espécies (dicotiledôneas + outras gramíneas + ciperáceas).

A estimativa de massa de forragem foi obtida considerando tanto o material verde quanto o material seco. Utilizou-se um aro com 0,25 m de diâmetro, o qual era lançado ao acaso dentro da subárea a cada 30 dias, em diferentes dos pontos amostrados para composição botânica, que foram previamente marcados. As amostras foram cortadas a $5 \mathrm{~cm}$ do solo e separadas por grupos/espécies. As amostras foram pesadas verdes, acondicionadas em sacos de papel, identificadas e colocadas em estufa com circulação forçada de ar, em temperatura constante de $55^{\circ} \mathrm{C}$, por 48 horas. A taxa de acúmulo de forragem por espécie foi obtida 
pelo quociente de massa total de forragem pelo número de dias do período e expressa em $\mathrm{kg}$ de MS/ha/dia.

Utilizou-se o delineamento de blocos ao acaso, com quatro tratamentos (60, 90, 120 e 150 dias) e cinco repetições. A composição botânica foi expressa em percentual do total. Os dados de massa de forragem e taxa de acúmulo de forragem foram analisados utilizando o programa SAS, e as médias comparadas por meio do LS MEANS, a 5\% de probabilidade.

\section{Resultados e Discussão}

A composição florística evidenciou a presença de 10 famílias, 15 gêneros e 18 espécies nos dois anos de avaliação. Entre as famílias com maior número de espécies está a Poaceae (= Gramineae), com sete espécies (Tabela 1).

Albuquerque et al. (2002), em área diferida em Caruaru, Pernambuco, identificaram 18 famílias, 32 gêneros e 36 espécies, e observaram também maior número de espécies da família Poaceae. Ydoyaga Santana et al. (2010), em pasto nativo no sertão de Pernambuco, identificaram no período chuvoso 24 famílias, 38 gêneros e 41 espécies, com maior número de espécies também da família Poaceae e Fabaceae no componente herbáceo. Possivelmente, o menor número de famílias observadas neste trabalho está relacionado ao batimento mais frequente do pasto.

Araújo Filho \& Carvalho (2002) afirmam que a caatinga apresenta número elevado de espécies botânicas. O número de espécies que compõem a caatinga é bastante variável, conforme o estrato considerado, o ano, a metodologia empregada e ações antrópicas (Santos et al., 2010). Outros autores (Moura, 1987; Reis, 2004; Moreira et al., 2006) também encontraram grande número de famílias e espécies no estrato herbáceo da caatinga, que mostra a complexidade e heterogeneidade desse ecossistema (Romariz, 1968). No entanto, esses autores enfocam que a maioria das espécies do estrato herbáceo no período chuvoso é pertencente à família Poaceae e é formada também por espécies anuais e perenes, como capim-milhã e capim-de-raiz, respectivamente. Neste sentido, Santos et al. (2009) observaram que as gramíneas foram as espécies quantitativamente mais importantes na dieta de ovinos na caatinga no período chuvoso. Ydoyaga-Santana et al. (2011) também observaram elevada presença de gramíneas na dieta de bovinos, com participação de $55 \%$ no início e $41 \%$ no final do período chuvoso.

Tabela 1 - Espécies e suas respectivas famílias presentes em área diferida, anos 2007 e 2008, São Bento do Una - Agreste de Pernambuco

\begin{tabular}{|c|c|c|}
\hline Famílias & Nome científico & Nome vulgar \\
\hline & Ano 2007 & \\
\hline Poaceae & Anthephora hermaphrodita (L.) Kuntze & Milha-de-arroz, capim-mimoso \\
\hline Poасеае & Digitaria ciliaris (Retz) Koel & Capim-colchão, capim-de-roça, capim-milhã \\
\hline Poасеае & Dactyloctaenium aegyptium (L.) Willd & Mão-de-sapo, mão-de-papagaio \\
\hline Poасеае & Digitaria horizontalis Willd. & Capim-colchão, capim-milhã, capim-de-roça \\
\hline Poасеае & Digitaria bicornis (Lam.) Roem \& Schult & Capim-sempre-verde \\
\hline Poасеае & Chloris orthonoton Doell & Capim-de-raiz \\
\hline Poaceae & Brachiaria plantaginea (Link.) & Capim-milhã, papuã, marmelada \\
\hline Nyctaginaceae & Boerhavia sp. & Pega-pinto \\
\hline Malvaceae & Sida spinosa $\mathrm{L}$ & Malva \\
\hline Amaranthaceae & Alternanthera tenella Colla & Ervanço \\
\hline Amaranthaceae & Froelichia humbodltiana Roem \& Schult & Caruru-verde \\
\hline Capparaceae & Cleome spinosa Jacq & Mussambê \\
\hline Boraginaceae & Heiliotropium angiospermum Murray & Fedegoso \\
\hline Rubiaceae & Diodia teres Walt & Engana-bobo \\
\hline & Ano 2008 & \\
\hline Рoасеае & Anthefhora hermafrodita (L.) Kuntze & Milha-de-arroz, capim-mimoso \\
\hline Poасеае & Digitaria ciliaris (Retz.) Koel. & Capim-colchão, capim-de-roça, capim-milhã \\
\hline Poaceae & Dactyloctenium aegyptium (L.) Willd & Mão-de-sapo, mão-de-papagaio. \\
\hline Рoасеае & Digitaria horizontalis Willd. & Capim-colchão, capim- milhã, capim-de-roça \\
\hline Роасеае & Digitaria bicornis (Lam.) Roem \& Schult & Capim-sempre-verde \\
\hline Poасеае & Chloris orthonoton Doell & Capim-de-raiz \\
\hline Poасеае & Brachiaria plantaginea (Link.) & Capim-milhã, papuã, marmelada \\
\hline Schrophulariaceae & Conobea scoparioides (Cham. \& Schltdl.) Benth & Pataqueira, vassourinha-do-brejo \\
\hline Malvaceaea & Sida procumbens $\mathrm{Sw}$ & Malva \\
\hline Malvaceae & Sida spinosa $\mathrm{L}$ & Malva \\
\hline Amaranthaceae & Alternanthera tenella Colla & Ervanço \\
\hline Amaranthaceae & Froelichia humbodltiana Roem \&Schult & Caruru-verde \\
\hline Сyperaceaea & Cyperus uncinulatus Schrad. Ex Nees & Barba-de-bode \\
\hline Boraginaceae & Heiliotropium angiospermum Murray & Fedegoso \\
\hline Mollunginaceae & Mollugo verticillata $\mathrm{L}$. & Sabão de soldado \\
\hline
\end{tabular}


Três espécies apresentam nome vulgar de capim-milhã: Brachiaria plantaginea, Digitaria ciliaris e Digitaria horizontalis (Tabela 1). Segundo relato de Pedralli (2002), nomes populares variam entre locais, de modo que uma mesma planta pode ter diversas denominações e um nome ser comum para diversas plantas. Assim, é importante a identificação pelo gênero e espécie, pois a variação do nome vulgar pode induzir a erros.

Albuquerque et al. (2002), trabalhando no Agreste pernambucano, também identificaram Brachiaria plantaginea como capim-milhã. No Sertão, YdoyagaSantana (2010) observaram que a B. plantaginea também aparece com nome vulgar de capim-milhã. Pode-se então afirmar que, pelo menos no Agreste e Sertão de Pernambuco, ao citar o capim-milhã, possivelmente se faz referência a B. plantaginea (Link) Hitchc.

Com relação à participação na composição botânica no período de maio a agosto de 2007, na área diferida (Figura 1), o capim-milhã foi o componente principal aos 60 e 90 dias, com percentuais de 46,75 e 52,09\% do total da composição. A partir deste ponto, sua presença foi menor.

Albuquerque et al. (2002), estudando componentes botânicos em área diferida no Agreste de Pernambuco, verificaram também participação expressiva do capim-milhã na composição botânica da pastagem, com valor de 33,08 \%. Por outro lado, neste mesmo estudo os autores encontraram presença de capim-de-raiz de $0,7 \%$, sendo este valor inferior aos de participação do capim-de-raiz da área em estudo, que foram todos acima de $10 \%$ (Figura 1). A variação na participação da milhã e do capim-de-raiz ao longo do período experimental indica sucessão no tempo. No início da estação chuvosa, o estrato herbáceo nos sítios ecológicos no semiárido é dominado por gramíneas do gênero Brachiaria e Paspalum efêmeras, em sua maioria. Segue-se, então, uma substituição de dominância, que passa a ser exercida dependendo do sítio e das características da estação por outras gramíneas e dicotiledôneas (Araújo Filho et al., 1995).

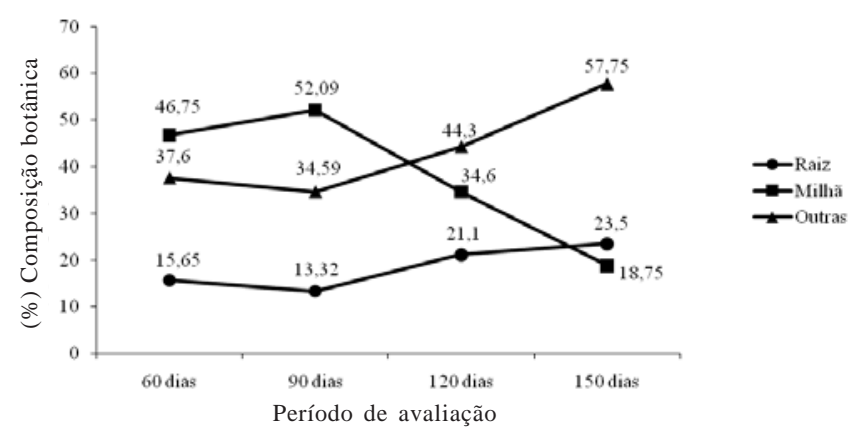

Figura 1 - Composição botânica do pasto nativo diferido nos diferentes períodos de avaliação, ano 2007.
Assim, aos 120 dias após o início das chuvas, o declínio da dominância do capim-milhã possibilitou o surgimento do capim-de-raiz. Fernandes et al. (1983) estudaram a composição botânica em pasto diferido de capim-de-raiz e encontraram participação de $49 \%$ do capim-de-raiz e $25 \%$ de leguminosas aos 90 dias e de 19 a 8,9\% aos 180 dias, respectivamente.

Vale ressaltar que a participação do capim-milhã na pastagem provavelmente contribui para melhoria na qualidade da forragem, uma vez que esta forrageira apresenta entre 10,5 e 14,61\% de proteína bruta, valores superiores à exigência mínima dos animais, que é de 7\% na matéria seca do pasto (Lançanova et al., 1988; Van Soest, 1994; Nascimento et al., 2002).

O capim-de-raiz está presente na composição botânica (Figura 1) no mesmo período que o capim-milhã, a partir dos 60 dias (15,65\%). No entanto, à medida que o capimmilhã aumenta, por ter desenvolvimento mais rápido, em participação na composição (52,09\%), a participação do capim-de-raiz diminui (13,32\%), voltando a aumentar em percentual quando o capim-milhã decresce $(34,6 \%)$ na composição botânica.

Segundo Cruz (1983), o capim-de-raiz atenderia às necessidades proteicas de mantença do animal entre 21 (16\%) e 42 (8\%) dias de idade, sendo que esses valores declinam rapidamente com o avanço da idade. Fernandes et al. (1993) estudaram o efeito do diferimento sobre o teor de proteína bruta de capim-de-raiz e encontraram teores de 10,1\% PB sem diferimento e 6\% PB com diferimento. O feno de capim-de-raiz colhido em plena floração apresentou alta porcentagem de fibra detergente neutro (FDN), em torno de $65 \%$, o que restringe seu uso como alimento exclusivo (Monteiro et al., 2009). Provavelmente, o feno decorrente da colheita nesta fase seria adequado como fonte de fibra, podendo ser utilizado, por exemplo, como alimento associado à palma forrageira, atendendo à deficiência de fibra da palma (Mattos et al., 2000).

Embora a variação da composição dependa das espécies presentes, neste estudo, observou-se aos 90 dias percentual de capim-de-raiz (13\%) bem inferior ao encontrado por Fernandes et al. (1983), que foi de $49 \%$, provavelmente porque a avaliação foi realizada em sítios ecológicos diferentes.

Ao final do ano de 2007, os maiores percentuais de participação foram apresentados pelo grupo "outras espécies” (57,75\%). Como esse grupo é constituído por espécies de baixo valor forrageiro, como espécies da família Malvaceae (Tabela 1), o pasto nesta época teria menor valor forrageiro. O diferimento por longo período de tempo provavelmente beneficia estas populações de outras espécies, prejudicando a associação capim-milhã + capim- 
de-raiz. Por outro lado, o diferimento até 90 dias pode ser considerado benéfico para a associação com maior percentual e, possivelmente, maior produção do capimmilhã, e o capim-de-raiz com provável composição química capaz de atender parte dos requerimentos nutricionais dos animais em pastejo.

O longo diferimento da área, que se estendeu até o ano de 2008, permitiu a dominância do grupo “outras espécies” (68,64\%) aos 60 dias após início das chuvas de março, chegando a $100 \%$ aos 150 dias de avaliação (Figura 2). Foi verificado no início das observações deste ano (60 dias), pequeno percentual de capim-de-raiz (2,31\%), quando, a partir dos 90 dias, nenhuma participação foi observada na composição botânica da área. Fernandes et al. (1983) afirmaram que diferimentos superiores a 180 dias, para pasto de capim-de-raiz e associação, acarreta o crescimento populacional de outras espécies, chegando a participação de $75 \%$ do total da composição florística. Neste estudo, o período foi mais longo e outras espécies chegaram a ocupar $100 \%$ da área diferida.

Foi observado um número expressivo de espécies herbáceas não-gramíneas e arbustivas, numa tendência ao retorno da comunidade original de espécies arbustivas da caatinga com o diferimento e a ausência do pastejo. Esse fato condiz com a hipótese de que o capim-de-raiz e o capimmilhã sejam subclímax e necessitem da presença do herbívoro e do controle permanente dos demais componentes da vegetação nativa para sua manutenção.

A massa de forragem (MF) diferiu $(\mathrm{P}<0,05)$ nas diferentes épocas de diferimento (Figura 3). O capim-milhã, no ano de 2007, apresentou maior massa de forragem aos 90 dias de diferimento, diferindo significativamente das demais épocas. Não houve diferença $(P>0,05)$ nos períodos 120 e 150 dias.

Aos 60 dias, o capim-milhã apresentou menor produção. Gomide (1998) orienta que, para aumentar a produção de leite por vaca em sistemas que utilizam lotação contínua, a disponibilidade de massa verde seca por ha deve ter valores entre 1.500 e $2.500 \mathrm{~kg}$. Neste sentido, Reis et al. (1997)

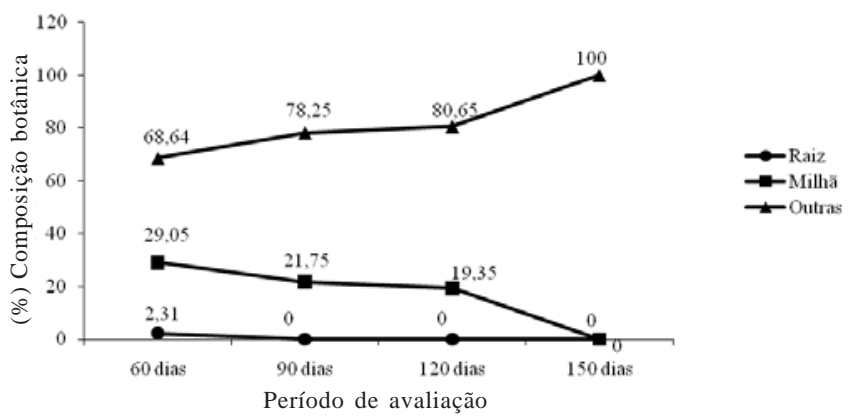

Figura 2 - Composição botânica do pasto nativo diferido durante diferentes períodos de avaliação, ano 2008

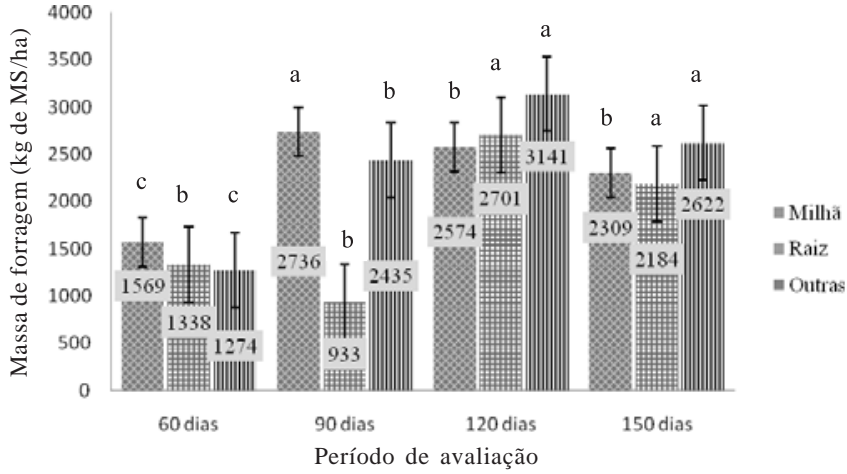

Médias seguidas de igual letra, não diferem entre si, pelo LS MEANS do SAS $(P>0,05)$. As barras representam os erros-padrão (capim-milhã - 280; capimde-raiz - 228 e outras - 142)

Figura 3 - Massa de forragem (kg de MS/ha) de capim-milhã, capim-de-raiz e outras em área de pasto nativo diferido, São Bento do Una - Pernambuco, 2007.

recomendam disponibilidade mínima de $2.000 \mathrm{~kg}$ de MS/ha, independentemente da qualidade. Albuquerque et al. (2002), estudando pastagem de Brachiaria decumbens e capins nativos diferidos no Agreste de Pernambuco, encontraram participações de disponibilidade de forragem de $704 \mathrm{~kg}$ de MS/ha, valor este inferior ao encontrado neste trabalho, com produção aos 90 dias de $933 \mathrm{~kg}$ de MS/ha ano.

Neste trabalho, em princípio aos 60 dias após o início das chuvas, a quantidade de massa de forragem atenderia à necessidade para produção de leite por vaca. É importante observar que, na determinação da massa da forragem, foi considerado tanto o material verde quanto o material seco. É provável que a disponibilidade possa estar sendo superestimada, tendo elevada disponibilidade de matéria seca, porém com baixo valor nutritivo.

As maiores médias para massa de forragem do capimde-raiz ocorreram aos 120 e 150 dias de diferimento, sendo superiores aos 60 e 90 dias, que por sua vez foram iguais em produção $(\mathrm{P}>0,05)$ (Figura 3$)$.

No Agreste de Pernambuco, o capim-de-raiz ocorre em associação com outras espécies em extensas áreas de pastagens nativas herbáceas, sendo frequentemente o principal componente da pastagem (Fernandes et al., 1983). A menor contribuição do capim-de-raiz coincide com a maior contribuição do capim-milhã na fitomassa e na composição botânica. Possivelmente aos 120 dias o declínio da dominância do capim-milhã possibilita o melhor desenvolvimento do capim-de-raiz. Fernandes et al. (1983) observaram no Agreste de Pernambuco, após três meses de diferimento do capim-de-raiz, valor de MF inferior $(1.488 \mathrm{~kg}$ de MS/ha). Neste trabalho, a produção total de matéria seca atingiu altos patamares, o que é condizente com a fertilidade do solo da área experimental. 
A massa de forragem de outras espécies aos 60 dias apresentou menor produção, quando comparada aos demais períodos; 90, 120 e 150 dias. Outras espécies em diferimento aos 120 dias apresentaram maior produção, quando comparado com a produção aos 60 e 90 dias, porém quando comparada aos 150 dias, foram semelhantes $(\mathrm{P}>0,05)$.

Sabendo que neste grupo existem espécies de baixo valor forrageiro, como é o caso da família Malvaceae (Tabela 1), o aumento da participação destas na composição botânica da pastagem possivelmente pode ter contribuído para maior redução da qualidade do pasto. Embora não tenha sido avaliada a qualidade da forragem, o conhecimento do valor das espécies indica que as espécies que passaram a predominar eram de menor valor forrageiro em comparação ao capim-de-raiz e capim-milhã.

A taxa de acúmulo de forragem foi diferente para as épocas de avaliação (Tabela 2). O capim-milhã apresentou maior taxa de acúmulo dos 60 aos 90 dias, que foi maior $(\mathrm{P}<0,05)$ nos períodos de 0 a 60,90 a 120 e 120 a 150 dias. Os períodos 0 a 60 e 90 a 120 não diferiram entre si ( $P>0,05)$. O período em que o capim-milhã apresentou menor taxa foi dos 120 a 150 dias.
A taxa de acúmulo no capim-de-raiz diminuiu no período de 60 a 90 dias, voltando a crescer aos 90 a 120 dias. Possivelmente o rápido crescimento do capim-milhã e de outras espécies interferiu no crescimento do capim-deraiz, contudo, com o declínio do crescimento do capimmilhã e das espécies anuais do grupo outras, o crescimento do capim-de-raiz foi favorecido

Para outras espécies, as maiores taxas de acúmulo ocorreram no período de 60 a 90 dias e foi superior $(\mathrm{P}<0,05)$ às produções dos períodos 0 a 60, 90 a 120 e 120 a 150 dias.

Considerando que a taxa de acúmulo do capim-milhã e do capim-de-raiz aos 120 dias foi superior a $41 \mathrm{~kg}$ de MS/ha, pode-se admitir lotação próxima a duas vacas por hectare neste período. Essa elevada lotação para condições de Agreste de Pernambuco é decorrente da elevada fertilidade do sítio ecológico avaliado. Neste sentido, vale informar que a pesquisa foi realizada em uma estação experimental que se dedica à seleção de gado holandês há muitos anos e onde a utilização de concentrados é uma prática corrente. O local do experimento, por ser próximo a central de manejo e ter área com arvores, tem frequentemente servido como área de repouso para as vacas em lactação, com consequente enriquecimento por transferência de nutrientes

Tabela 2 - Taxa de acúmulo de forragem (kg de MS/ha/dia) em pasto nativo diferido, São Bento do Una - Pernambuco, 2007

\begin{tabular}{|c|c|c|c|c|c|}
\hline \multirow[t]{2}{*}{ Espécie } & \multicolumn{4}{|c|}{ Período (dias) } & \multirow[t]{2}{*}{ Erro-padrão } \\
\hline & $0-60$ & $60-90$ & $90-120$ & $120-150$ & \\
\hline Milhã & $26,1 \mathrm{~b}$ & $45,6 a$ & $21,45 b$ & $15,4 c$ & 7,6 \\
\hline Outras & $21 b$ & $40,6 a$ & $26,2 b$ & $17,5 \mathrm{c}$ & 3,6 \\
\hline
\end{tabular}

Médias seguidas de igual letra na linha não diferem $(\mathrm{P}>0,05)$ entre si pela comparação de médias LS MEANS do SAS.

\section{Conclusões}

A redução na massa e na participação da composição botânica do capim-milhã ao longo do período avaliado sugere que o aproveitamento da forragem acumulada dessa espécie deve ocorrer preferencialmente dos 60 aos 90 dias, após o início das chuvas, enquanto que a de capim-de-raiz dos 90 a 120 dias. Após um ano sem interferência humana ou de animais, o capim-de-raiz e o capim-milhã diminuem a participação na composição botânica do pasto, tendendo o retorno do sítio ecológico ao clímax da caatinga.

\section{Agradecimentos}

Ao Conselho Nacional de Desenvolvimento Científico e Tecnológico (CNPq), pelo apoio financeiro e à Fundação de Amparo à Ciência e Tecnologia do Estado de Pernambuco
(FACEPE), pela concessão de bolsa à primeira autora. Ao Instituto Agronômico de Pernambuco (IPA), pela parceria na realização da pesquisa.

\section{Referências}

ALBUQUERQUE, S.S.C.; LIRA, M.A.; SANTOS, M.V.F. et al. Utilização de diferentes fontes de nitrogênio associadas à palma forrageira (Opuntia fícus indica Mill) cv Gigante na suplementação de vacas leiteiras mantidas em pasto diferido. Revista Brasileira de Zootecnia, v.31, p.1315-1324, 2002.

ARAÚJO FILHO, J.A.; CARVALHO, F.C. Desenvolvimento sustentado da caatinga. In: ALVAREZ, V.H.; FONTES, L.E.F.; FONTES, M.P.F. (Eds). O solo nos grandes domínios morfoclimáticos do Brasil e o desenvolvimento sustentado. Viçosa, MG: SBCS; UFV, DPS, 1997. p.125-133.

ARAÚJO FILHO, J.A.; SOUZA, F.B.; CARVALHO, F.C. Pastagens no semiárido: Pesquisa para o desenvolvimento sustentável. In: SIMPÓSIO SOBRE PASTAGENS NOS ECOSSISTEMAS BRASILEIROS - PESQUISA PARA O DESENVOLVIMENTO SUSTENTÁVEL, 1995, Brasília. Anais... Brasília: Sociedade Brasileira de Zootecnia, 1995. p.63-75. 
ARAÚJO FILHO, J.A.; CARVALHO, F.C.; SILVA, N.L. Fenología y valor nutritivo de follajes de algunas especies forrajeras de la Caatinga. Agroflorestería en las Américas, v.9, p.33-37, 2002.

CRUZ, M.S.D. Germinação e crescimento do capim-de-raiz (Chloris orthonoton Doell). 1983. 59f. Dissertação (Mestrado em Botânica) - Universidade Federal Rural de Pernambuco, Recife.

FERNANDES, A.P.M.; FARIAS, I.; LIRA, M.A. et al. Efeito de diferentes períodos de diferimento sobre o pasto de capim-deraiz (Chloris orthonoton Doell). In: CONGRESSO BRASILEIRO DE FORRAGEIRAS E PASTAGENS NATIVAS, 1., 1983, Olinda. Anais... Olinda: IPA, 1983. s.n.p.

GOMIDE, J.A. Fatores de produção de leite a pasto. In: CONGRESSO NACIONAL DOS ESTUDANTES DE ZOOTECNIA, 1998, Viçosa, MG. Anais... Viçosa, MG: Conez, 1998. p.1-32.

LANÇANOVA, J.A.C.; RESTLÉ, J.; SANTOS, G.L. Digestibilidade e produção de matéria seca digestível do capim papuã (Brachiaria plantaginea (Link) Hitch) sob efeito de freqüências de corte e nitrogênio. Ciência Rural, v.18, n.3-4, p.319-327, 1988.

MARASCHIN, G.E. Perdas de forragem sob pastejo. In: SIMPÓSIO SOBRE ECOSSISTEMA DE PASTAGENS, 2., 1993, Jaboticabal. Anais... Jaboticabal: FUNEP/UNESP, 1993. p.166-190.

MARQUES C.B. [2007]. Tipos de pastagens, sob o ponto de vista ecológico. Disponível em: <http://www.agronline.com.br/ agrociencia/artigo.php/47/abstract.> Acesso em: 12 oct. 2009.

MATTOS, L.M.E.; FERREIRA, M.A.; SANTOS, D.C. et al. Associação da palma forrageira (Opuntia fícus indica Mill) com diferentes fontes de fibra na alimentação de vacas 5/8 HolandêsZebu em lactação. Revista Brasileira de Zootecnia, v.29, n.6, p.2128-2134, 2000.

MONTEIRO, C.C.F.; GUIM, A.; SOUZA, E.J.O. et al. Composição química e digestibilidade de nutrientes do feno de capim-de-raiz (Chloris orthonoton Doell) em ovinos. In: JORNADA DE ENSINO, PESQUISA E EXTENSÃO, 6., 2009, Recife. Anais... Recife: Universidade Federal Rural de Pernambuco, [2009] (CD-ROM).

MOURA, J.W.S. Disponibilidade e qualidade de pastos nativos e de capim Buffel (Cenchrus Ciliaris L.) diferido no semiárido de Pernambuco. 1987. 159f. Dissertação (Mestrado em Nutrição Animal) - Universidade Federal Rural de Pernambuco, Recife.

MOREIRA, J.N.; LIRA, M.A.; SANTOS, M.V.F. et al. Caracterização da vegetação de Caatinga e da dieta de novilhos no Sertão de Pernambuco. Pesquisa Agropecuária Brasileira, v.41, n.11, p.1643-1651, 2006.

NASCIMENTO, M.P.S.C.B.; RENVOIZE, S.A; NASCIMENTO, H.T.S. Gramíneas da Região de Mimoso no Piauí. Teresina: Ministério da Agricultura Pecuária e Abastecimento, 2002. (Comunicado Técnico, 144).
OLIVEIRA, T.N.; PAZ, L.G.; SANTOS, M.V.F. et al. Influência do fósforo em diferentes regimes de cortes na produtividade e no perfilhamento do capim-de-raiz (Chloris orthonoton Doell). Revista Brasileira de Zootecnia, v.33, n.1, p.60-67, 2004.

PEDRALLI, G.; CARMO, C.A.S.; CEREDA, M. et al. Uso de nomes populares para espécies de Araceae e Discoreaceae no Brasil. Horticultura Brasileira, v.20, n.4, p.530-532, 2002.

REIS, A.M.S. Organização do extrato herbáceo de uma área de caatinga de Pernambuco em anos consecutivos. 2004. 55f. Dissertação (Mestrado em Botânica) - Universidade Federal Rural de Pernambuco, Recife.

REIS; R.A.; RODRIGUES, L.R.A; PEREIRA, J.R.A. A Suplementação como estratégia de manejo da pastagem. In: SIMPÓSIO SOBRE MANEJO DA PASTAGEM, 13., 1996, Piracicaba. Anais... Piracicaba: FEALQ, 1997. p.23-50.

ROMARIZ, D.A. A vegetação. In: AZEVEDO, A. (Ed.) Brasil a terra e o homem: as bases físicas. 2.ed. São Paulo: Nacional, 1968. p.521-62.

SANTOS, G.R.A.; BATISTA, A.M.V.; GUIM, A. et al. Composição química e degradabilidade in situ da ração em ovinos em área de caatinga no sertão de Pernambuco. Revista Brasileira de Zootecnia, v.38, n.2, p.384-391, 2009.

SANTOS, M.V.F.; LIRA, M.A.; DUBEUX JÚNIOR et al. Potential of Caatinga forage plants in ruminant feeding. Revista Brasileira de Zootecnia, v.39, p.204-215, 2010 (supl. especial).

SILVA, N.L.; ARAÚJO FILHO, J.A.; SOUSA, F.B.S. et al. Pastoreio de curta duração com ovinos em caatinga raleada no sertão Cearense. Pesquisa Agropecuária Brasileira, v.34, n.1, p.135-140, 1999.

SILVA, F.B.R.; SANTOS, J.C.P; SILVA, A.B. et al. Zoneamento agroecológico do estado de Pernambuco. Recife: Embrapa Solos - UEP Recife/SPRRA, 2001. (Documentos, 35). (CD-ROM).

STATISTICAL ANALYSES SYSTEM - SAS. SAS/STAT: user's guide, version 8, Cary: 1999. 1464p.

T'MANNETJE, L.T; HAYDOCK, K.P. The dry-weight-rank method for the botanical analysis of pasture. Journal British Grassland Society, v.18, n.4, p.268-275, 1963.

THORNTHWAITE, C.W.; MATHER, J.R. The water balance. Ceterton: Drexel Institute of Technology-Laboratory of Climatology, 1955. 104p. (Publications in Climatology, v.8, n.1).

TOTHIL, J.C. Regional course on measurement of grassland vegetation. Santiago: FAO, 1979. 76p.

VAN SOEST, P.J. Nutritional ecology of the ruminant. New York: Cornell University Press, 1994. 476p.

YDOYAGA-SANTANA, D.F.; LIRA, M.A.; SANTOS, M.V.F. et al. Caracterização da caatinga e da dieta de novilhos fistulados, na época chuvosa, no semiárido de Pernambuco. Revista Brasileira de Zootecnia, v.40, n.1, p.69-78, 2011. 